\title{
Characterization of Fusarium spp. Causing Potato Dry Rot in China and Susceptibility Evaluation of Chinese Potato Germplasm to the Pathogen
}

\author{
Miru Du • Xiangyu Ren • Qinghua Sun • Yi Wang • \\ Ruofang Zhang
}

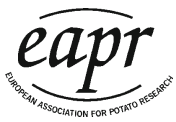

Received: 14 May 2011 / Accepted: 10 June 2012 /

Published online: 11 July 2012

(C) The Author(s) 2012. This article is published with open access at Springerlink.com

\begin{abstract}
Dry rot is a serious potato disease and causes significant losses in China. Research efforts on potato dry rot have been very limited as well as the attempts to characterize the pathogen in the major potato production regions of China. A total of 260 Fusarium isolates were identified in 698 potato tubers collected in six important potato production regions of northern China, out of which five different Fusarium species, Fusarium sambucinum, $F$. avenaceum, $F$. oxysporum, $F$. equiseti, and $F$. acuminatum, were isolated. The identification of each species was confirmed by sequencing analysis of $\sim 700$ bp DNA fragment derived from the translation elongation factor-1 alpha gene. F. sambucinum was found to be the predominant species accounting for $56 \%$ of the isolates. Different pathogenicity was found to be associated with five most common Fusarium species. Sixty-seven clones used in China were identified as susceptible to $F$. sambucinum, indicating little scope for developing resistant cultivars using the currently available potato germplasm.
\end{abstract}

Keywords Fusarium · Pathogenicity · Potato dry rot

\section{Introduction}

Dry rot caused by Fusarium species is an important potato disease worldwide and causes post-harvest rotting and seed piece decay after planting. Dry rot of seed tubers

Electronic supplementary material The online version of this article (doi:10.1007/s11540-012-9217-6) contains supplementary material, which is available to authorized users.

M. Du $\cdot$ X. Ren $\cdot$ Q. Sun $\cdot$ Y. Wang $\cdot$ R. Zhang $(\bowtie)$

Inner Mongolia Potato Engineering and Technology Research Centre, Inner Mongolia University, 235

West College Road, Hohhot 010021 Inner Mongolia, P.R. China

e-mail: ruofang_zhang@yahoo.com.cn 
can reduce crop establishment by affecting the development of potato sprouts and causing crop losses up to $25 \%$, while more than $60 \%$ of tubers can be infected during storage (Wharton and Kirk 2007). Other tuber diseases, such as soft rot and late blight, often accompany dry rot leading to more serious damages. It has been reported that this disease causes post-harvest losses costing US producers US\$100-250 million annually (http://www.ars.usda.gov/is/AR/archive/jun02/fungus0602.pdf, 2008). Post-harvest losses can be as high as $28 \%$ in the prefecture of Dingxi located in Gansu Province, China, out of which, 88\% are due to dry rot (He et al. 2004).

Fusarium is a large genus of Ascomycota fungi, with a few hundred species mainly distributed in soils and in association with plants (Summerell et al. 2010). Many species are pathogens of economically important crops. It can cause vascular wilts, root, stalk, and cob rots, collar rot of seedlings, and rots of tubers, bulbs, and corms in a wide range of plants. Thirteen different Fusarium species have been identified as agents responsible for potato dry rot worldwide (Cullen et al. 2005). The pathogenicity of these species varies significantly (Choiseul et al. 2007; Peters et al. 2008a) depending on the potato cultivar and temperature during inoculation (Wastie et al. 1989; Esfahani 2005). Two Fusarium species, $F$. sambucinum (formally $F$. sulphureum) and $F$. coeruleum, have been reported to be the principal causes of potato dry rot under temperate conditions (Corsini and Pavek 1986). Several Fusarium species caused potato dry rot in Iran with $F$. sambucinum and F. solani being the predominant species (Esfahani 2005). In Great Britain, potato dry rot was mainly attributed to four Fusarium species: $F$. coeroleum, $F$. avenaceum, $F$. culmorum, and $F$. sambucinum, with $F$. coeroleum being the predominant species (Peters et al. 2008a). F. avenaceum was associated with storage rot of potatoes in other European countries (Satyaprasad et al. 1997) and Northeastern USA (Hanson et al. 1996).

Dry rot is strictly regulated by seed certification standards in developed countries. However, in China, standard seed potato production has been initiated only in recent years and no regulations on dry rot have been so far applied, which may be a major factor in recent epidemics of Fusarium dry rot in the country. Few potato dry rot studies have been conducted in China. Ye and Wang (1994) collected a total of 168 Fusarium isolates from potato tubers in Zhejiang Province of China. These isolates were classified into nine species and subspecies. F. sambucinum and F. solani were found to be the pathogenic species associated with potato tuber dry rot in Gansu Province of China ( $\mathrm{Li}$ et al. 2007). However, there are no published reports on the importance or etiology of dry rot in northern China, an important region for both ware and seed potato production. The research reported here aimed: (1) to survey the Fusarium species associated with dry rot in major potato production regions in northern China; (2) to investigate the distribution and pathogenicity of different Fusarium species; and (3) to evaluate likely resistance of available potato germplasm to dry rot.

\section{Materials and Methods}

The occurrence of suspicious potato dry rot disease in storage facilities was identified by inquiring all major potato producers in northern China. All the suspicious sites had 
been visited. A total of 698 potato tubers with dry rot symptoms were collected from 60 storage cellars in 2007 and 2009 from Inner Mongolia Autonomous Region and Ningxia Hui National Autonomous Region and four provinces: Gansu, Heilongjiang, Shanxi, and Hebei. The samples were processed immediately on arrival. Potato clones used in dry rot susceptibility evaluation (Supplementary Table 1) were provided by several potato breeding programs in China.

\section{Identification of Different Fusarium Species}

Dry rot-infected potato tubers were washed thoroughly with water, surface-sterilized for 3 min with $1.5 \%$ sodium hypochlorite, and washed twice with sterile distilled water. Tubers were cut and infected tissue was excised from the edge of the lesion or from the inside of potato dry cavity. The infected tissue was then cultured on potato dextrose agar supplemented with $100 \mathrm{mg} / \mathrm{ml}$ ampicillin. Plates were incubated at $25{ }^{\circ} \mathrm{C}, 60 \%$ relative humidity, and under a 12 -h alternation of light and dark. Single spore cultures were obtained by dilution series. After 4 days of single spore culture, colony diameter was measured and morphological characters were recorded. All isolates were identified using morphological characteristics of colony and conidia, including growth ratio and pigment of colony, size and shape of conidia, and other morphological structures, according to published descriptions (Booth 1971; Leslie and Summerell 2006).

\section{Phylogenetic Analysis of Fusarium Isolates Using a Molecular Marker}

DNA of 41 purified single spore cultures was extracted using the CTAB method (Odonnell and Cigelnik 1997). Two primers were used to amplify a 700-bp fragment specific to the translation elongation factor- 1 alpha (TEF- $1 \alpha$ ) gene of the Fusarium spp.: forward primer, 5'-ATGGGTAAGGAAGACAAGAC-3', and reverse primer, 5'GGAGGTACCAGTGATCATGTT-3' (Geiser et al. 2004). Polymerase chain reaction (PCR) was performed in $50 \mu \mathrm{l}$ mixture containing DNA template (50-100 ng), 10× Ex Taq buffer (10 mM Tris-HCl, $2.5 \mathrm{mM} \mathrm{MgCl}_{2}, 50 \mathrm{mM} \mathrm{KCl,} \mathrm{pH} \mathrm{8.3),} 0.25 \mathrm{mM}$ each dNTP, $0.2 \mu \mathrm{M}$ of each primer, and $1.25 \mathrm{U}$ Ex Taq DNA polymerase. PCR reaction consisted of one cycle of initial denaturation at $94{ }^{\circ} \mathrm{C}$ for $85 \mathrm{~s}$, followed by 33 cycles of denaturation at $95{ }^{\circ} \mathrm{C}$ for $30 \mathrm{~s}$, and primer annealing at $58{ }^{\circ} \mathrm{C}$ for $55 \mathrm{~s}$, extension at $72{ }^{\circ} \mathrm{C}$ for $2 \mathrm{~min}$, and finally $72{ }^{\circ} \mathrm{C}$ for $10 \mathrm{~min}$. All PCR products were sequenced directly. Sequencing data were aligned and clustered by Mega 4.0 (Tamura et al. 2007). A bootstrap maximum parsimony tree was constructed with Aspergillus niger (accession NW001594204) as outgroup and bootstrapped 1,000 replicates to check the robustness of clades.

\section{Pathogenicity Test}

Potato cultivar Favorita is susceptible to Fusarium dry rot in practice (http:// www.europotato.org/display_description.php?variety_name=Favorita). Disease-free tubers of Favorita were inoculated with seven Fusarium isolates to assess the pathogenicity of different Fusarium species (Table 1). Tubers were washed with $1.5 \%$ sodium hypochlorite solution for $3 \mathrm{~min}$ and rinsed with water and allowed to 
Table 1 Average lesion size on tubers of potato cultivar Favorita after inoculation with one of five Fusarium species

The same letter means no significant difference; $t=2.015$, at level $\alpha=0.05$, NIC noninoculated control

\begin{tabular}{ll}
\hline Isolate (species) & Average lesion size $(\mathrm{mm})$ \\
\hline NM13-2-S $(F$. avenaceum $)$ & $27.500 \mathrm{a}$ \\
NM6-1-S $(F$. oxysporum $)$ & $26.944 \mathrm{a}$ \\
NM5-1-S $(F$. sambucinum $)$ & $24.167 \mathrm{a}$ \\
NM1-4-S $($ F. oxysporum $)$ & $16.778 \mathrm{~b}$ \\
NM5-3-J $($ F. acuminatum $)$ & $16.278 \mathrm{~b}$ \\
NM5-1-J $(F$. acuminatum $)$ & $14.661 \mathrm{~b}$ \\
NM2-1-S $(F$. equiseti $)$ & $13.611 \mathrm{~b}$ \\
NIC & $0.000 \mathrm{c}$ \\
\hline
\end{tabular}

dry overnight. The interior part of the tubers was individually wounded with an 11$\mathrm{mm}$ diameter drill with a depth of $11 \mathrm{~mm}$. An 11-mm agar plug derived from the edge of a 7-day-old colony was inserted in the drilled tuber hole. Six tubers were incubated and placed in a cardboard box at $25^{\circ} \mathrm{C}$ in dark for 20 days. The tubers were then cut through the inoculation site and the depth and width of the rot area were measured. A control treatment consisting of a non-inoculated agar plug inserted into the wounded tuber was also included in the evaluation. The data were analysed with SAS (version 9.0, SAS Institute Inc.) and means were separated with Duncan's multiple range test.

\section{Dry Rot Susceptibility Evaluation}

A total of 67 potato clones including 21 cultivars and 46 breeding lines (Supplementary Table 1) were selected to test their resistance to $F$. sambucinum (NM5-1-S), which is the most dominant pathogenic Fusarium species in pathogenicity evaluation. All tested tubers were free of visible disease symptoms and weighed from 100 to $150 \mathrm{~g}$. Healthy tubers were surface-sterilized with $75 \%$ ethanol and wounded using the similar method described above. The inoculated tubers, five per each clone, were then placed in a cardboard box at $16{ }^{\circ} \mathrm{C}$ for 20 days. Data collection and analysis were similar to those used in the pathogenicity test.

\section{Results}

\section{Collection and Identification of Fusarium Species}

Potato dry rot was a serious post-harvest disease in 2007 and 2009 in several provinces located in the northern and western regions of China, including the Inner Mongolia Autonomous Region, Ningxia Hui National Autonomous Region, and the provinces of Gansu, Heilongjiang, Shanxi, and Hebei. The average yield losses due to dry rot and reported by this survey varied from 5 to $20 \%$ in the above locations. This variability was likely due to the highly variable storage conditions, the Fusarium species, and their different pathogenicity. We obtained a total of 260 different Fusarium isolates from 698 potato tubers collected in these 2 years, out of which five species were identified (Table 2 and Supplementary Table 2). F. sambucinum and $F$. avenaceum were the most dominant species among these isolates, which accounted 
Table 2 The number of isolates associated with different Fusarium species from potato tubers collected in northern and western China in 2007 and 2009

\begin{tabular}{lrrc}
\hline Species & 2007 & 2009 & Proportion (\%) \\
\hline F. sambucinum & 33 & 113 & 56.2 \\
F. avenaceum & 6 & 72 & 30.0 \\
F. oxysporum & 6 & 18 & 9.2 \\
F. equiseti & 1 & 7 & 3.1 \\
F. acuminatum & 3 & 1 & 1.5 \\
Total & 49 & 211 & 100.0 \\
\hline
\end{tabular}

for approximately 56 and $30 \%$ of the collection, respectively (Table 2). Isolates of these two species were found in the tubers collected from different areas. F. sambucinum was the predominant species in five out of six of the surveyed potato-growing areas, while $F$. avenaceum was the predominant species in Gansu Province (Table 3).

\section{Genetic Differences Among the Isolated Fusarium Species}

In order to verify classification of these five species based on the morphological characteristics, we sequenced a region of TEF- $1 \alpha$ gene of 41 isolates randomly selected from the 260 isolates. The variation of TEF-1 $\alpha$ gene sequences has been used in parallel with other morphological characteristics to correctly identify Fusarium species (Geiser et al. 2004). All of the sequences showed a high similarity (more than 95\%) with those of known Fusarium strains in GenBank (http:// www.ncbi.nlm.nih.gov/genbank). Phylogeny analysis showed that the sequences could be divided in four groups (Fig. 1). Group I isolates were exclusively $F$. sambucinum. Group II and group III isolates were closer to each other than to the other groups. Group II included both $F$. avenaceum and F. acuminatum, two species with a similar morphology. In group III, isolate NMJC2-1 was morphologically

Table 3 Distribution of five Fusarium species isolated from potato tubers issued from six potato-growing areas in China showing dry rot symptoms

\begin{tabular}{lllllll}
\hline Province origin & $\begin{array}{l}\text { Sample } \\
\text { number }\end{array}$ & $\begin{array}{l}\text { F. sambucinum } \\
(\%)\end{array}$ & $\begin{array}{l}\text { F. avenaceum } \\
(\%)\end{array}$ & $\begin{array}{l}\text { F. oxysporum } \\
(\%)\end{array}$ & $\begin{array}{l}\text { F. equiseti } \\
(\%)\end{array}$ & $\begin{array}{l}\text { F. acuminatum } \\
(\%)\end{array}$ \\
\hline $\begin{array}{l}\text { Inner Mongolia } \\
\text { Autonomous }\end{array}$ & 262 & 59.5 & 28.1 & 7.2 & 2.6 & 2.6 \\
$\quad \begin{array}{l}\text { Region } \\
\text { Ningxia Hui }\end{array}$ & 41 & 46.7 & 20.0 & 6.7 & 26.7 & - \\
$\quad \begin{array}{l}\text { Autonomous } \\
\text { Region }\end{array}$ & & & & & & \\
$\begin{array}{l}\text { Gansu } \\
\text { Province }\end{array}$ & 90 & 41.9 & 45.2 & 12.9 & - & - \\
$\begin{array}{c}\text { Heilongjiang } \\
\text { Province }\end{array}$ & 80 & 54.5 & 21.2 & 24.2 & - & - \\
$\begin{array}{c}\text { Shanxi } \\
\text { Province }\end{array}$ & 23 & 70.0 & 30.0 & - & - & - \\
Hebei Province & 25 & 55.6 & 44.4 & - & - & - \\
\hline
\end{tabular}


similar with other $F$. oxysporum isolates. However, the TEF-1 $\alpha$ gene sequence of NMJC2-1 was different from other $F$. oxysporum isolates and was classified as $F$. oxysporum var. redolens. The latter was considered partially different genetically from most $F$. oxysporum species, but basically similar in terms of biological characters. Group IV was represented by a single isolate of $F$. equiseti. Thus, the identification of species based on morphological characteristics matched well with the phylogenetic data (Supplemental Table 2 and Fig. 1).

\section{Pathogenicity of the Fusarium Species}

All of the tested isolates caused rot on tubers of cv. Favorita. Tubers inoculated with isolate NM13-2-S of $F$. avenaceum showed a mean lesion size of $27.50 \mathrm{~mm}$, the highest average lesion size among all tested isolates (Table 1). Tubers inoculated with isolate NM5-1-S of F. sambucinum had a mean lesion size of $24.17 \mathrm{~mm}$, which is not significantly different from the lesion size caused by $F$. avenaceum. These two Fusarium species, however, showed significantly higher pathogenicity than F. acuminatum and $F$. equiseti, based on average lesion sizes (Table 1). We also observed significantly different pathogenicity associated with two isolates of $F$. oxysporum. Tubers of cv. Favorita inoculated with isolate NM6-1-S showed a similar lesion size than tubers inoculated with $F$. avenaceum and $F$. sambucinum; whereas tubers inoculated with isolate NM1-4-S showed a similar lesion size than tubers inoculated with $F$. acuminatum and $F$. equiseti (Table 1). On the other hand, we did not find any difference between the two isolates of $F$. acuminatum based on lesion sizes.

Species differed in pathogenicity with the most pathogenic one causing lesions about twice the size of those least pathogenic. Based on Duncan's test, species fell into one of the two groups. The most pathogenic species, $F$. avenaceum, F. oxysporum, and $F$. sambucinum, belonged to one group, while the less pathogenic group comprised $F$. acuminatum, $F$. equiseti, and the $F$. oxysporum isolate NM1-4-S.

\section{Susceptibility of Potato Cultivars to Fusarium Species}

All 67 tested potato clones were susceptible to F. sambucinum with lesion sizes ranging from 20 to $48 \mathrm{~mm}$, showing a continuum of variation (Supplementary Table 1 and Fig. 2). Désirée and a few clones showed the smallest infection sizes. Most of the clones tested were breeding lines and the majority of them were more susceptible than the cultivar Désirée. Overall, there were no significantly resistant sources in the materials tested.

\section{Discussion}

At least thirteen Fusarium species have been considered as causal agents of dry rot of potato worldwide (Cullen et al. 2005). Five Fusarium species, F. sambucinum, F. avenaceum, F. oxysporum, $F$. equiseti, and $F$. acuminatum, were found in our survey covering six important potato-growing areas in northern China. This classification is supported by phylogenetic analysis using a representative molecular marker, which is able to identify different species of Fusarium (Geiser et al. 2004). Six additional species, 


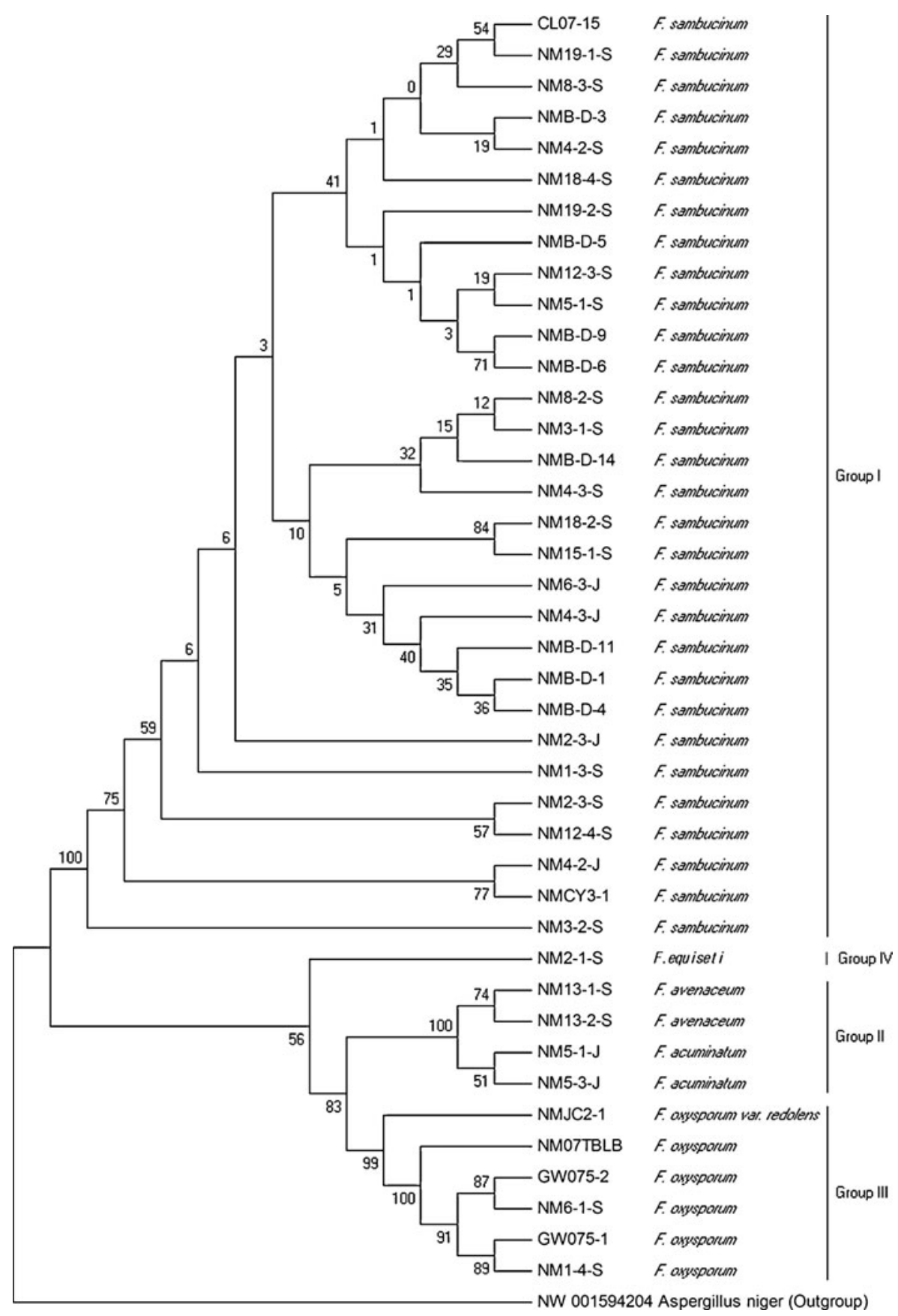

Fig. 1 Phylogenic tree showing relationships of 41 Fusarium spp. isolates based on 700-bp sequences derived from the TEF- $1 \alpha$ gene using the maximum parsimony method. Bootstrap values are shown next to the branches

including F. solani, F. semitectum, F. culmorum, F. moniliforme, F. trichothecioidos, and $F$. sporotrichioides were previously reported to be associated with potato dry rot in China with F. solani being the most frequently reported species (Li 1992; Ye and 


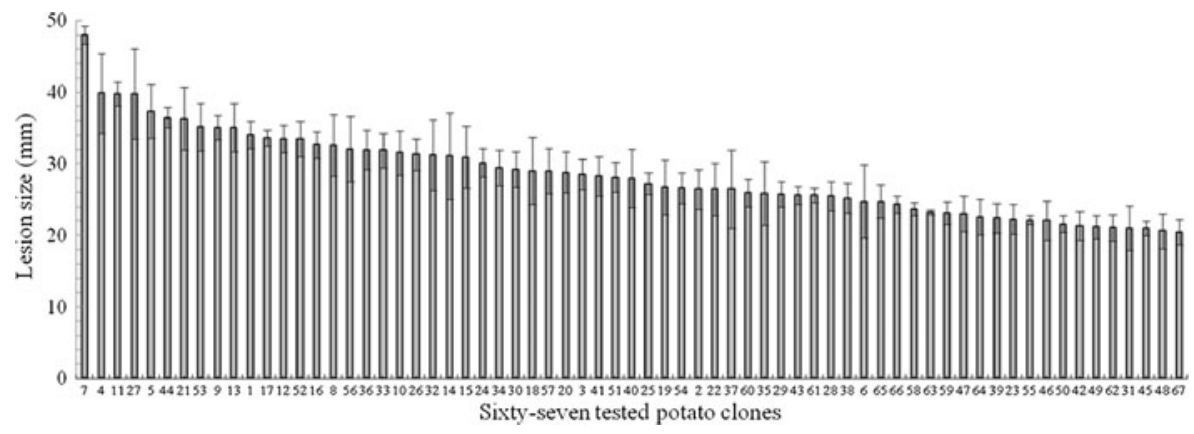

Fig. 2 Susceptibility of 67 potato clones to F. sambucinum (isolate NM5-1-S). The 67 potato clones are listed in Supplementary Table 1. The $Y$-axis represents lesion size and the number listed on $X$-axis represents the code no. of each clone

Wang 1994; Peng and Zhu 2008). Ye and Wang (1994) collected 168 Fusarium isolates in a previous survey carried out in Zhejiang Province, which is, however, a less important potato-growing region than those considered in this article. Several factors may explain why different Fusarium species were identified in the present survey compared to that implemented by Ye and Wang (1994), including use of different rotation patterns and different potato cultivars, as well as different environmental and/or edaphic conditions. The present survey shows that $F$. sambucinum and $F$. avenaceum are currently the most dominant species responsible for potato dry rot in northern China. F. sambucinum was identified as the most prevalent species causing dry rot in Gansu Province of China. These results were confirmed by Li et al. (2007), while $F$. solani has frequently been identified as one of the most common dry rot causing species (Hanson et al. 1996; Choiseul et al. 2007; Peters et al. 2008a; Peters et al. 2008b). It was, however, not present in the present survey. These results support the highly dynamic nature of different Fusarium species as the causal agents of potato dry rot. The first three highly pathogenic species are also the most dominant species in this survey, suggesting that the predominant distribution of Fusarium species is likely associated with its pathogenicity.

Losses caused by potato dry rot can be minimized by chemical control with thiabendazole, which is applied to tubers during post-harvest operations. However, increasing resistance of $F$. sambucinum to thiabendazole has been reported in the USA, Canada, and Europe (Desjardins 1995; Gonzalez et al. 2002). The most effective and environmentally friendly approach to control dry rot is the utilization of resistant potato cultivars, although better handling of potatoes at harvest and during post-harvest operations would sensibly reduce the importance of such disease as well. Only cursory germplasm evaluation on resistance to Fusarium dry rot has been reported in the literature (Leach and Webb 1981; Corsini and Pavek 1986; Wastie and Bradshaw 1993; Lynch et al. 2003; Esfahani 2005; Valluru et al. 2006). Tested clones include commercial cultivars and breeding lines, showing varying degrees of susceptibility but one breeding line with immunity to two Fusarium species. However, potato cultivars and breeding lines generally show susceptibility to different Fusarium species worldwide.

In spite of the fact that dry rot is a major potato storage disease in China, there has been little, if any, breeding efforts to improve the dry rot resistance of potato cultivars. We examined the dry rot susceptibility of major Chinese potato clones including 
cultivars and breeding lines to the predominant species $F$. sambucinum. This is the first evaluation of Chinese potato germplasm for susceptibility to potato dry rot pathogens. Désirée is in the most tolerant group to the isolate of $F$. sambucinum. The previous work also showed that Désirée was ranked as the second highest tolerant cultivar to $F$. sambucinum (Esfahani 2005). Our results showed that the majority of the potato lines are moderately and highly susceptible to F. sambucinum. Thus, we infer that there is very limited dry rot resistance in the current Chinese potato germplasm due to their narrow genetic background. Identification and introduction of resistant germplasm from a wider germplasm collection would be a key step to breed dry rot resistant potato cultivars. The importance of controlling potato bruises due to poor handling practices at harvest and during post-harvest operations is another means for prevention of tubers losses caused by potato dry rot. Losses due to potato dry rot may be also accentuated by poor ventilation in the stores and consequent risks of condensation on the superficial part of the bulked potatoes during winter time.

Acknowledgments We thank Jiming Jiang for critical revision of this manuscript and Yufeng Wu for help on the phylogenetic analysis. We thank Liping Jin, Zhen Du, and Xiufeng Gong for providing potato cultivars and breeding lines that were tested in the reported experiments. We also thank Wanmin Sheng and Ying Shi (Heilongjiang Province), Yihang Wang and Yulin Pu (Gansu Province), and Jiang Yin (Hebei Province) for their help in collecting diseased samples. This research was funded by Modern Agro-industry Technology Research System (no. nycytx-15) from the Ministry of Science and Technology of the People's Republic of China, China Agriculture Research System (CARS-10), and National Key Technology R\&D Program (no. 2007BAD49B00) from the Ministry of Agriculture of the People's Republic of China.

Open Access This article is distributed under the terms of the Creative Commons Attribution License which permits any use, distribution, and reproduction in any medium, provided the original author(s) and the source are credited.

\section{References}

Booth C (1971) The genus Fusarium. Commonwealth Agricultural Bureaux [for the] Commonwealth Mycological Institute, Great Britain

Choiseul J, Allen L, Carnegie SF (2007) Fungi causing dry tuber rots of seed potatoes in storage in Scotland. Potato Res 49:241-2533

Corsini D, Pavek JJ (1986) Fusarium dry-rot resistant potato germplasm. Am Potato J 63:629-6384

Cullen DW, Toth IK, Pitkin Y, Boonham N, Walsh K, Barker I, Lees AK (2005) Use of quantitative molecular diagnostic assays to investigate Fusarium dry rot in potato stocks and soil. Phytopathology 95:1462-1471

Desjardins AE (1995) Population structure of Gibberella pulicaris (anamorph Fusasrium sambucinum) from potato tuber dry rot in North America and Europe. Am Potato J 72:145-156

Esfahani MN (2005) Susceptibility assessment of potato cultivars to Fusarium dry rot species. Potato Res 48:215-226

Geiser DM, Jimenz GMM, Kang S, Mkalowska I, Veeraraghavan N, Ward TJ, Zhang N, Kuldau GA, O’Donnell K (2004) FUSARIUM-IDv.1.0: A DNA sequence database for identifying Fusarium. Eur J Plant Pathol 110:473-479

Gonzalez CF, Provin EM, Zhu L, Ebbole DJ (2002) Independent and synergistic activity of synthetic peptides against thiabendazole-resistant Fusarium sambucinum. Phytopathology 92:917-924

Hanson LE, Schwager SJ, Loria R (1996) Sensitivity to thiabendazole in Fusarium species associated with dry rot of potato. Phytopathology 86:378-384

He SQ, Jin XL, Wei ZQ, Zhang TY, Du X, Luo DG (2004) Isolates and identification of pathogens causing dry rot of potato tubers in Ding Xi prefecture of Gansu province. J Yunnan Agric Univ (Nat Sci) 19:550-552 
Leach SS, Webb RE (1981) Resistance of selected potato cultivars and clones to Fusarium dry rot. Phytopathology 71:623-629

Leslie JF, Summerell BA (2006) The Fusarium laboratory manual. Wiley, New York

Li KL (1992) The dry rot of potato in Hohhot. Acta Sci Nat Univ Intramongolicae 23:429-433

Li JH, Chai ZX, Wang D, Li MQ (2007) Isolation and identification of the pathogens of potato fungus diseases during storage in Gansu Province. J Lanzhou Univ (Nat Sci) 101:39-43

Lynch DR, Kawchuk LM, Chen Q, Kokko M (2003) Resistance to Fusarium sambucinum in wild and cultivated Solanum species. Am J Potato Res 80:353-358

Odonnell K, Cigelnik E (1997) Two divergent intragenomic rDNA ITS2 types within a monophyletic lineage of the fungus Fusarium are nonorthologous. Mol Phylogenet Evol 7:103-116

Peng XW, Zhu JH (2008) Variety and distribution of potato fungi disease in Hebei Province. Chin Potato J 22:31-33

Peters JC, Lees AK, Cullen DW, Sullivan L, Stroud GP, Cunnington AC (2008a) Characterization of Fusarium spp. responsible for causing dry rot of potato in Great Britain. Plant Pathol 57:262-271

Peters RD, MacLeod C, Seifert KA, Martin RA, Hale LR, Grau CR, MacInnis S (2008b) Pathogenicity to potato tubers of Fusarium spp. isolated from potato, cereal and forage crops. Am J Potato Res 85:367374

Satyaprasad K, Bateman GL, Read PJ (1997) Variation in pathogenicity on potato tubers and sensitivity to thiabendazole of the dry rot fungus Fusarium avenaceum. Potato Res 40:357-365

Summerell BA, Laurence MH, Liew ECY, Leslie JF (2010) Biogeography and phylogeography of Fusarium: a review. Fungal Divers 44:3-13

Tamura K, Dudley J, Nei M, Kumar S (2007) MEGA4: molecular evolutionary genetics analysis (MEGA) software version 4.0. Mol Biol Evol 24:1596-1599

Valluru R, Christ BJ, Haynes KG, Vinyard BT (2006) Inheritance and stability of resistance to Fusarium tuber rot in tetraploid potatoes. Am J Potato Res 83:335-341

Wastie RL, Bradshaw JE (1993) Inheritance of resistance to Fusarium spp. in tuber progenies of potato. Potato Res 36:189-193

Wastie RL, Stewart HE, Brown J (1989) Comparative susceptibility of some potato cultivars to dry rot caused by Fusarium sulphureum and F. solani var. coeruleum. Potato Res 32:49-55

Wharton P, Kirk W (2007) Fusarium dry rot. http://www.potatodiseases.org/dryrot.html

Ye QM, Wang GC (1994) On Fusarium dry rot of potato in Zhejiang. Acta Phytopathol Sin 25:14 